\title{
DE HABITACIÓN DE SERVICIO A RIVAL DE LA SALA DE ESTAR. UNA PEQUEÑA HISTORIA DE LA COCINA EN FRANCIA, DEL SIGLO XX AL XXI ${ }^{1}$
}

FROM SERVANTS' HALL TO LIVING ROOM
COMPETITOR. A BRIEF HISTORY OF THE KITCHEN IN
FRANCE, FROM THE $20^{\text {TH }}$ TO THE $21^{\text {ST }}$ CENTURIES

Monique Eleb

École Nationale Supérieure d'Architecture

Paris-Malaquais

Entregado el 6-8-2012 y aceptado el 3-5-2013.

Resumen: La cocina es la estancia doméstica que más ha evolucionado a lo largo del siglo $\mathrm{xx}$, pasando de espacio sucio $-\mathrm{y}$ por lo tanto relegado en el plano de la casa - a rival de la sala de estar como territorio de la sociabilidad familiar, y condicionando la composición de la vivienda. Se convierte desde finales del siglo XIX en un lugar privilegiado para la higiene en el que «reina» un ama de casa que, una vez va desapareciendo el servicio doméstico, la transforma en una estancia principal; trasladándose en consecuencia a la fachada y cercana al comedor. A esta migración se sumaría un cambio radical en el acondicionamiento de la pieza, que pasará a contar con mobiliario y equipamiento especializado, surgiendo entonces modelos que perpetuarán su vigencia hasta la actualidad. Pasará también a ser un escenario en el que exhibir el estatus de la familia, pasando de ser algo que esconder a una posesión que mostrar.

Palabras clave: cocina, comedor, espacio doméstico, equipamiento culinario, distribución y sociabilidad familiar, cultura material, distribucion y disposición espacial.

1 Traducción de Jorge Uría. 


\begin{abstract}
The kitchen is the domestic dependency that has most evolved throughout the $20^{\text {th }}$ century. It has ceased to be a dirty space-therefore relegated within the house planning - and turned into a competitor to the living room as an area of family sociability, thus conditioning the household structure. Since the end of the $19^{\text {th }}$ century, the kitchen has been turned into a privileged room for hygiene in which the housewife has «reigned». She has transformed it into a prominent dependency, once the domestic service has gradually disappeared. Consequently, it has been moved to a front position, close to the dining room. In addition to this shift, a radical change has operated in the furnishing of this space, which has been endowed with specialised furniture and equipment and, in turn, models have emerged which have perpetuated its relevance until today. The kitchen has also become an area in which the status of the family can be shown and it has ceased to be a room that should be hidden to become a part of the house that must be exhibited.
\end{abstract}

Key words: kitchen, dining room, domestic space, culinary equipment, family sociability, material culture, spatial distribution and disposition. 


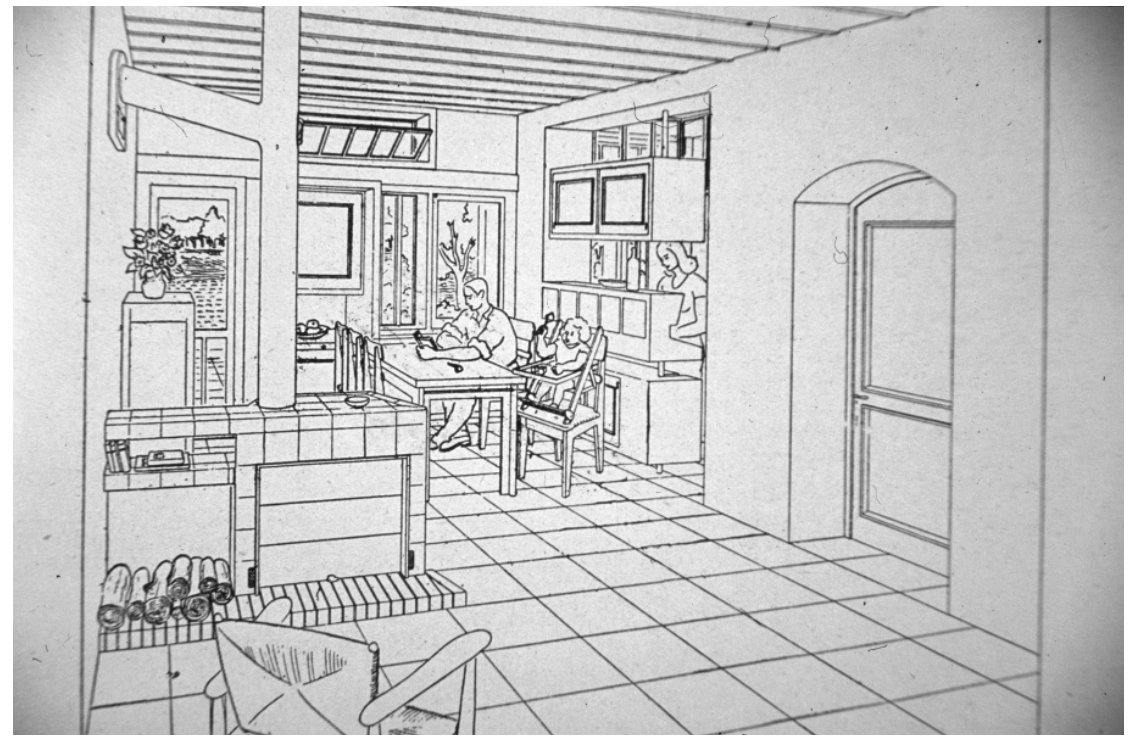

Figura 1

Cocina con pasa-platos abierta hacia la sala de estar en Terrier (Aisne); diseño de Jean Bossu, arquitecto, Techniques \& Architectures, n. ${ }^{\circ}$ 5-6, 1974, p. 247.

Desde que me intereso por la evolución de las formas de vida y las concepciones arquitectónicas en Francia, casi todas mis obras incluyen un capítulo sobre la cocina, puesto que refleja los cambios de costumbres y estructura el plano de la casa ${ }^{2}$. Su lugar, su forma, su apertura, su ilumi-

${ }^{2}$ Sobre el particular véase, de Monique Eleb Penser l'habité; le logement en questions, Pierre Mardaga, Paris-Liège, 1988 (con M. Châtelet y T. Mandoul); Architectures de la vie privée; maisons et mentalités. XVIIIe-XIXe siècles, Fernand Hazan, Paris, 1999 (con Anne Debarre-Blanchard); L'apprentissage du chez soi; le Groupe des Maisons Ouvrières, avenue Daumesnil, Paris, 1908, Parenthèses, Marseille, 1994; L'invention de l'habitation moderne, Paris, 1880-1914. Architectures de la vie privée. Hazan, Paris, 1995 (con Anne DebarreBlanchard); Urbanité, sociabilité et intimité. Des logements d'aujourd'hui, Editions de l'Epure, Paris, 1996 (con A. M. Châtelet); Préfabriquer la tradition. La 3e voie de la maison individuelle (1920-1960), ACS, Paris, 2002 (con Lionel Engrand); Vu de l'intérieur. Habiter un immeuble en île-de-France, 1945-2010, Archibooks, Paris, 2011 (con Sabri Bendimérad); Entre confort, désirs et normes. Le logement contemporain: 1995-2010, Mardaga, Paris, 2013 (con Philippe Simon); Les 101 mots de l'habitat à l'usage de tous, Archibooks, Paris, 2014. 
nación han sido objeto de mil reflexiones, a menudo contradictorias; y ha ido inclinándose hacia tipos distintos, escogidos de modo preferente por algunas corrientes doctrinales ${ }^{3}$.

La cocina es la pieza que más ha evolucionado en el curso del siglo Xx, dado que ha pasado de espacio de servicio relegado al fondo del piso, a un lugar definido como principal puesto que deviene en el territorio de la sociabilidad familiar ${ }^{4}$. Espacio para la suciedad, transformándose y desplazándose hacia la fachada, la cocina ha adquirido el estatus de rival de la sala de estar de la que, por otra parte, es a menudo un peculiar enclave.

En esta cocina escondida de principios del siglo xx, los objetos y muebles colocados al azar se transforman pronto en fijos y, conectándose a una red, pasan a señalarse como «equipamientos». Ello constituye una revolución de no poca cuantía, puesto que el carácter fijo de las canalizaciones imprime su huella en la organización de la vivienda. Reagrupar estas dotaciones se manifiesta muy pronto como algo necesario para bajar los costes. Para comprender su evolución, además, es preciso considerar la del trabajo doméstico que afecta a las relaciones hombre/mujer, así como la de las técnicas y dispositivos arquitectónicos.

En la distribución del hábitat aristocrático y burgués, que heredamos, la cocina era el espacio de lo sucio y de la «gente inmunda» y debía ser alejada de los espacios de recepción. Fue preciso transformar esta imagen de «último lugar de la insalubridad» en la casa, y reflexionar sobre su concepción, para hacerla un espacio privilegiado de la higiene y al mismo tiempo entronizar allí al «ama de casa», la perfecta ama de casa». Con motivo de la definición del Reglamento parisino de urbanismo de 1902, los arquitectos se preguntan si la cocina es una pieza principal concluyendo que, con la desaparición del servicio doméstico de las residencias ${ }^{5}$,

3 Sobre la cocina del Movimiento Moderno véase sobre todo Catherine Clarisse, Cuisine, recettes d'architecture, les éditions de l'imprimeur, Besancon, 2004

${ }^{4}$ Una primera versión de este texto ligeramente modificado, con algunas ilustraciones diferentes, ha sido publicado con motivo de la Exposición Vu de l'intérieur. Habiter un inmueble en Ile de France (1945-2010), (de la que fui Comisaria junto con Sabri Bendimérad), 19 de enero-23 de febrero de 2011. El catálogo con el mismo título (coautor Sabri Bendimérad, con dos artículos de Thierry Roze y Lionel Engrand) fue publicado por Archibooks/Ordre des Architectes d'Ile de France, en 2011.

5 «Nosotros vemos incluso a personalidades eminentes organizar su cocina con un cuidado meticuloso para hacer vida allí; pero por otra razón: la desaparición del servicio doméstico que ha transformado al ama de casa en "chica para todo"», escribe en 1950 
el «ama de casa» se hace presente allí convirtiéndola en una estancia principal. Se traslada, en consecuencia, a la fachada.

A finales del siglo XIX la cocina está ligada a la escalera y al patio de servicio, en la parte trasera de la casa en el hábitat burgués. Con su traslado hacia el comedor, se enriquece inmediatamente con un office para conformar una distribución confortable que disocie lo presentable y lo no presentable: la cocina estaba todavía escondida, mientras que el office permitía exhibir las pertenencias al mismo tiempo que adornar las fuentes de servir antes de que pasasen al comedor. Este último, que daba antes sobre el patio, llega a la fachada de los inmuebles colectivos a finales del siglo XIX, respaldando los ritos burgueses que valorizan la vida de familia y la reunión en el momento de las comidas; y llega a ser el rival del salón formando un sistema con el office y la cocina. Los invitados pueden ver el office ocasionalmente, jamás la cocina. Esta organización se convierte en algo banal en el hábitat burgués hasta los años de 1950.

\section{El surgimiento de la cocina equipada y racional}

A esta migración se añade un cambio radical del acondicionamiento de esta pieza, dado que había sido durante siglos amueblada de cualquier manera, con pequeñas mesas que se codeaban con las grandes, taburetes y pequeñas estanterías sobrecargadas, jarras y cacerolas dispuestas no importa dónde. Los muebles de la cocina son ligeros, móviles. Pero se fijarán, primero, en la vivienda social y filantrópica de principios del siglo XX. Armarios empotrados especializados (para escobas, para cacerolas...), superficies de trabajo, fregaderos vinculados a redes de agua corriente, cocinas de gas con campana, constituyen la primera cocina equipada en la «sala común». El surgimiento de esta cocina racional, acerca de cuyo ordenamiento se reflexiona, se traslada al seno de equipos pluridisciplinares de sociedades filantrópicas que inventan la vivienda social en Francia. La Sociedad del Grupo de Casas Obreras (GMO, Fundación Lebaudy), propone por vez primera en 1905 una pequeña cocina, equipada

\footnotetext{
Albert Laprade, observador desde hacía ya tiempo de las costumbres de sus contemporáneos y de la producción arquitectónica (en la «Introducción» de Albert Laprade a Habitations Collectives. Documents présentés par Pierre Bourget. Impr. Strasbourgeoise, Strasbourg, 1950, p. 6.
} 


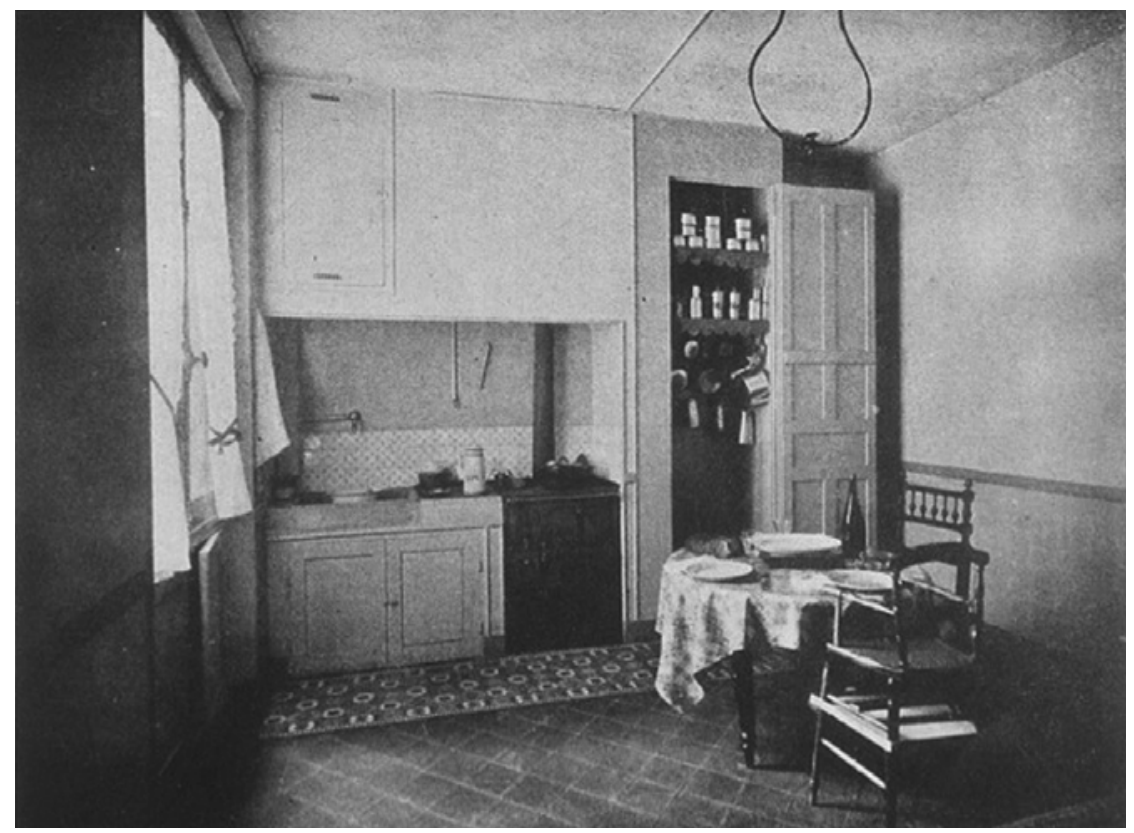

\section{Figura 2}

Cocina equipada de la operación «rue Ernest Lefèvre», arquitecto Auguste Labussière, GMO, 1905.

en la sala común, que se adoptará como parte resolutiva por parte de los Congresos internacionales de $\mathrm{HBM}^{6}$ para las clases populares ${ }^{7}$.

Esta cocina va a influir hasta hoy mismo en la nuestra, o al menos en la que todavía es su forma mayoritaria: todo debe desaparecer una vez que se ha terminado de cocinar y comer. En la sala común la cocina se vuelve invisible puesto que tiene que poder arreglarse todo clausurándola de alguna manera. Estos filántropos observan la transformación de estas cocinas (luz, superficies de trabajo, ventilación, mantenimiento, eficacia de la chimenea, etc.), que al mismo tiempo ellos mismos mejoran.

${ }^{6} \mathrm{HBM}$, movimiento de cooperativas de Habitation à Bon Marché (nota de la traducción).

7 Cf. el capítulo «La cuisine et ses transformations» de nuestra obra (con Anne Debarre) L'invention de l'habitation moderne. Paris, 1880-1914, op. cit., pp. 119-138. 


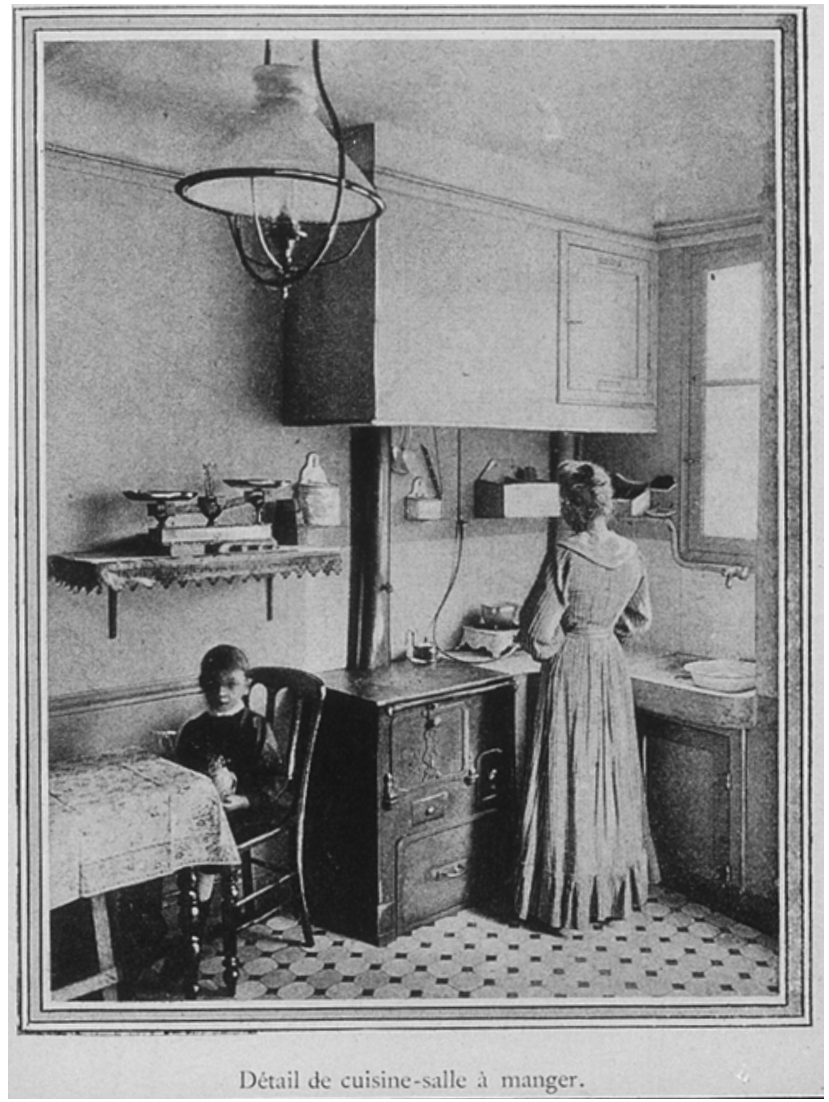

Figura 3

Cocina equipada en la sala común, Calle Amiral Roussin, Auguste Labussiére, GMO, 1907.

Tres años más tarde, proponen en 1908 para la población más pobre una cocina abierta, en alcoba.

Esta cocina perdura y Albert Laprade la evoca intentando hacer emerger la tendencia a principios de los años cincuenta: «Por ahora la cocina de tamaño medio, o cocina de alcoba abriéndose sobre una gran sala común, comparte los parabienes de los arquitectos». Recordemos que para mejor 


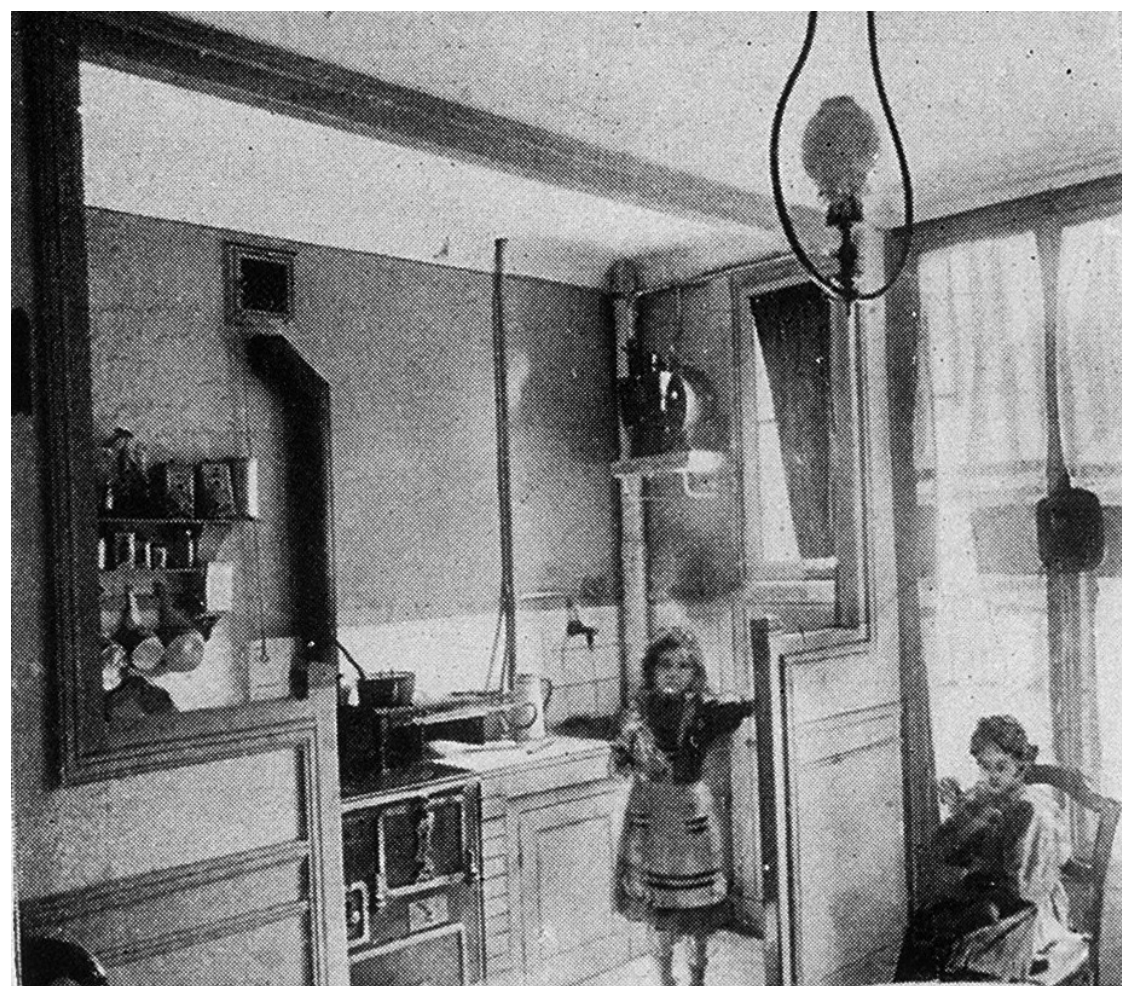

Figura 4

Cocina de alcoba en sala común. Inmueble de la Avenida Daumesnil, arquitecto Auguste Labussière, GMO, 1908

vender esta cocina de alcoba y desligarla de su imagen originariamente popular, los promotores de los años sesenta la denominarán «cocina americana».

Este momento de invención de la cocina abierta y equipada es también el de una reflexión sobre el trabajo doméstico. Christine Frederick, autora en 1913 de The New Housekeeping 8 , y Paulette Bernège, que va a

8 Es decir, «La nouvelle maitresse de maison», véase también L'organisation ménagère moderne. Du taylorisme chez-soi, Dunod, Paris, 1927. 


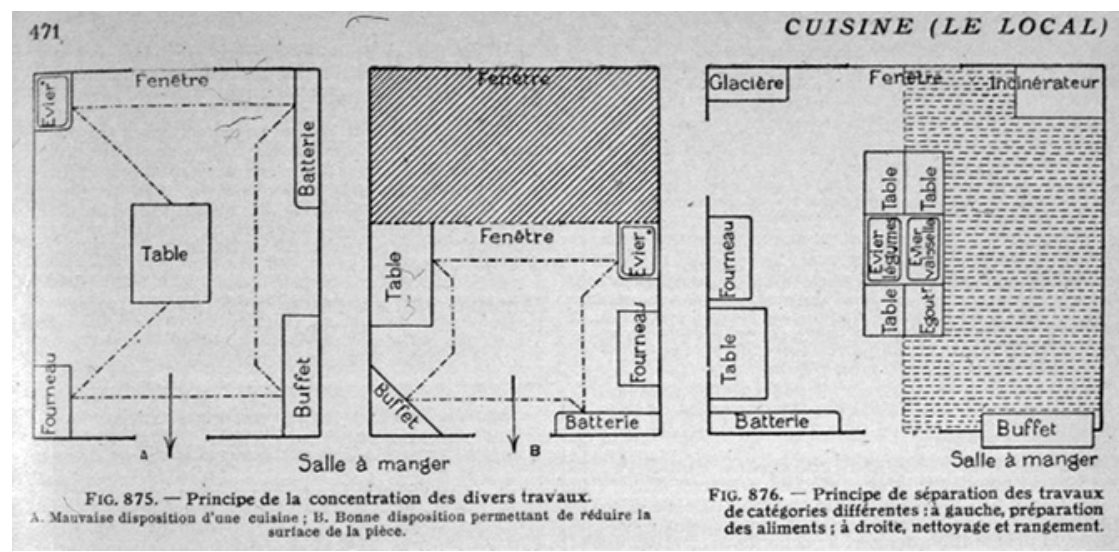

Figura 5

Distribución de la cocina buena y mala, y principio de separación de los trabajos. Larousse ménager illustré, 1926.

difundir sus ideas en Francia ${ }^{9}$, piensan que éste debe ser racionalizado y que es preciso practicar el «taylorismo en casa» ${ }^{10}$. La mujer en $s u$ cocina está como en una fábrica y es preciso estudiar las acciones y los gestos para llegar a concebir una cocina racional y funcional. La cocina se concibe a partir del período de entreguerras en torno a tres «centros» que corresponden a tres tipos de actividades. Preparar, cocinar, lavar/arreglar/ volver a poner en orden, y sus diferentes funciones, van a ser durante todo el siglo XX la base de la reflexión sobre su organización; puesto que se trata de racionalizar para disminuir «los pasos del ama de casa» dado que una «mala cocina», mal organizada, fatiga. El ama de casa hace un trabajo serio, además de minuciosamente estudiado, y es preciso que se beneficie de todos los saberes de la ciencia ${ }^{11}$ incluso en la cocina mínima. El placer está raramente presente en estos razonamientos.

9 Autora sobre todo de Si les femmes faisaient les maisons, Orléans, Mon chez-moi, 1928.

10 El libro de Catherine Beecher, The american womens's home, de 1869, va a ser fundamental en esta línea.

${ }^{11}$ La talla de la mujer y la altura de las mesas de trabajo se armonizan. Cuando la talla varíe en 2 centímetros, la altura varía en 1 centímetro, estableciéndose el óptimun de los panelados de las alturas. Nótese que el hombre no se registra como existente en la cocina 


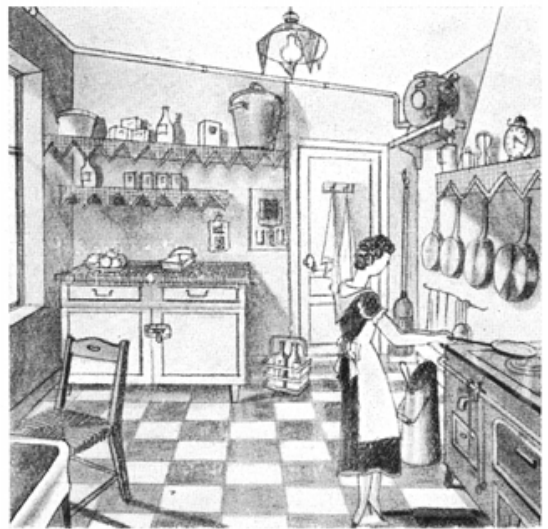

LA MAUVAISE CUISINE

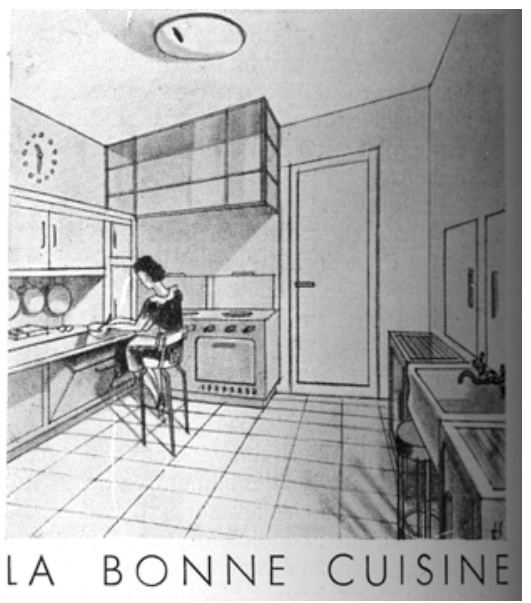

Figura 6

La mala cocina, la buena cocina.

Michel Dufet, Meubles, ensembles, décors, Edition du Décor d'aujourd'hui, juillet 1945.
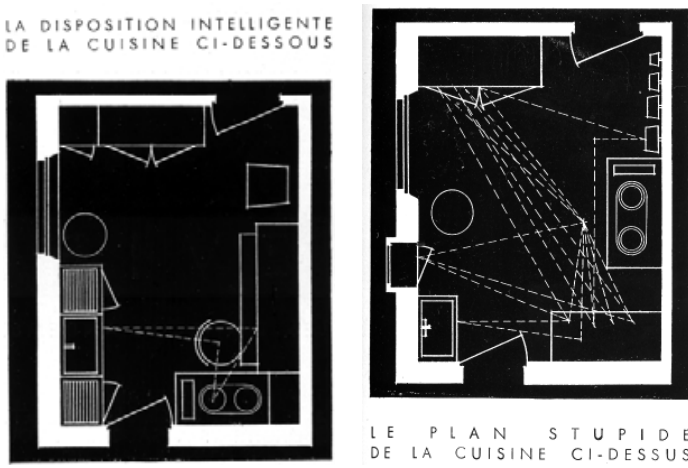

LE PLAN ST U P I DE DE LA CUISINE CI.DESSUS
DANSLACUISINE DE GAUCHE POUR FAIRE UNE OME LETTE IL FAUT $29 O P E R A T I O N S$ $D O N T$ I 8 DÉPLACEMENTS. DANS CEL$L E$ DE DROITE $P O U R$ L A M E ME O MELETTE IL FAUT 14 OPERA $T 1 O N S$ DONT 2 DÉPLACEMENTS

Figuras 7 y 7 bis

Dos planos de «La mala cocina/la buena cocina».

Comentario opus cit. 


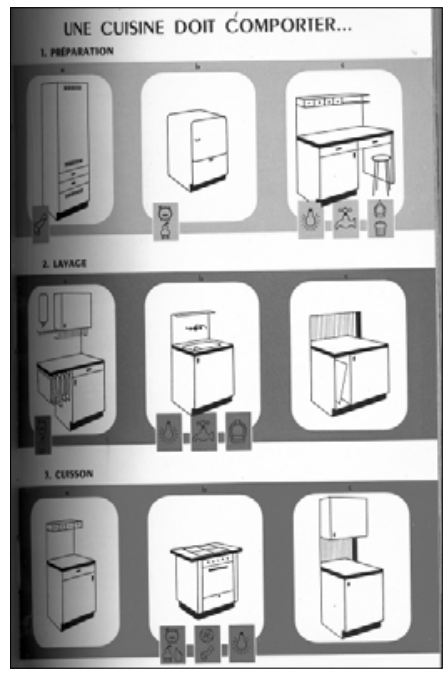

\section{Figura 8}

«Una cocina debe suponer... Preparación, lavado, cocción». L'Art ménager français, Flammarion, 1952.
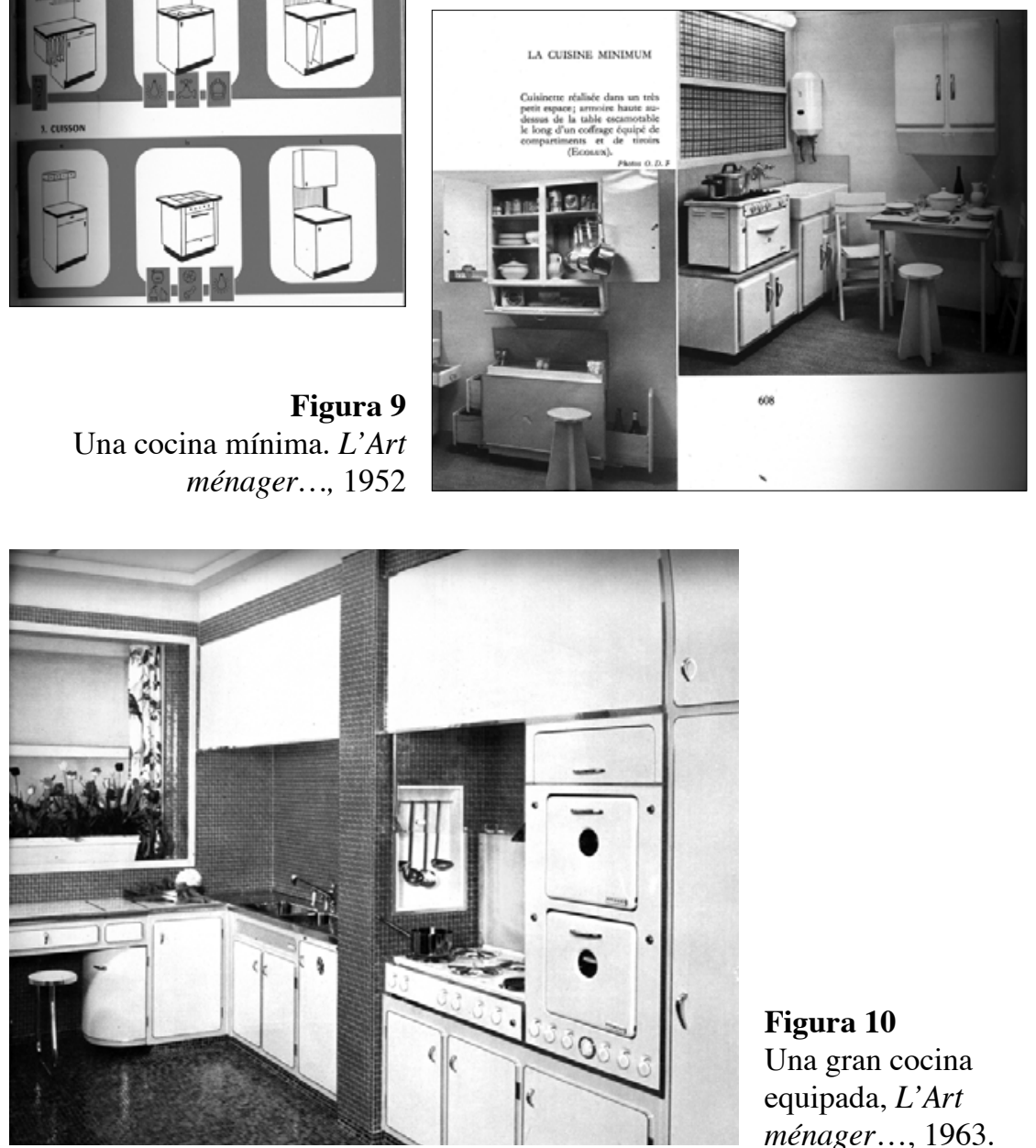

Figura 10

Una gran cocina equipada, L'Art ménager..., 1963. 


\section{La cocina laboratorio}

La historia oficial de la arquitectura, que no ha integrado todavía la aportación de las Fundaciones filantrópicas, estima que la famosa «cocina de Francfort» es la primera que marca el siglo Xx. Erns May trabaja con Gretta Shutte-Lihotsky, arquitecta vienesa, que se interesa en el diseño y la decoración. Ella pondrá a punto, entre 1926 y 1930, esta muy pequeña cocina funcional, cocina-laboratorio, que ha tenido tanto éxito.

Más larga que ancha $(1,87 \mathrm{~m}$. por 3,44 m.) va a reproducirse hasta hoy dado que sirve para la vivienda de superficie reducida. Es muy criticada por numerosos usuarios debido a su estrechez, que hace difícil permanecer allí

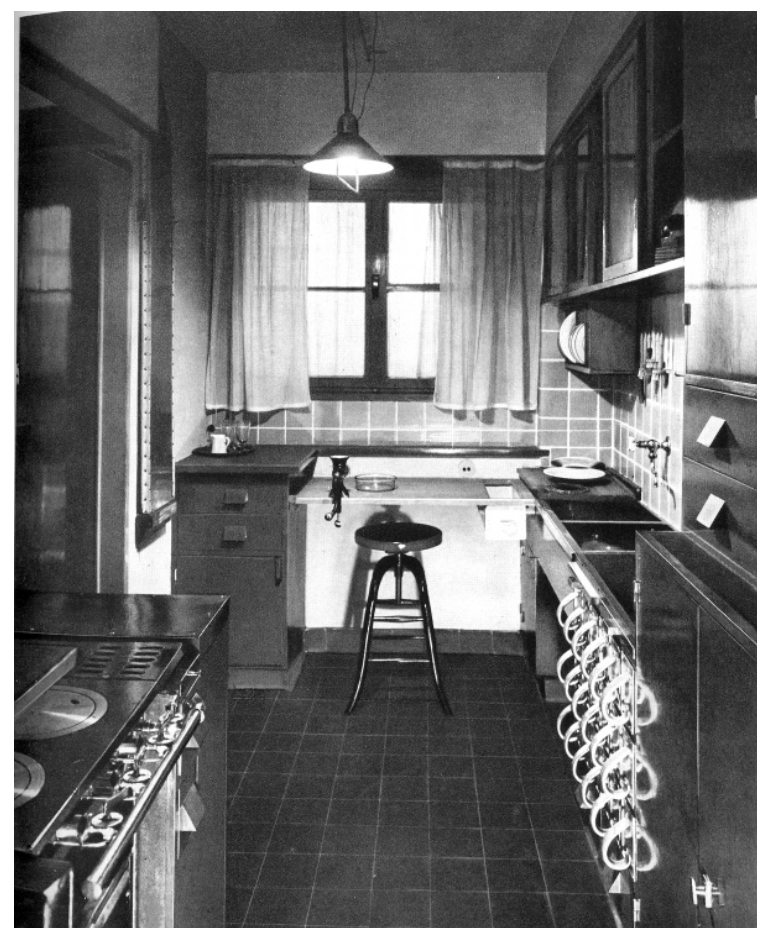

Figura 11

La «cocina de Francfort». Arquitectos Ernst May y

Grette Chutte-Lihotsky, 1926 y 1930. L'Art ménager..., 1963. 


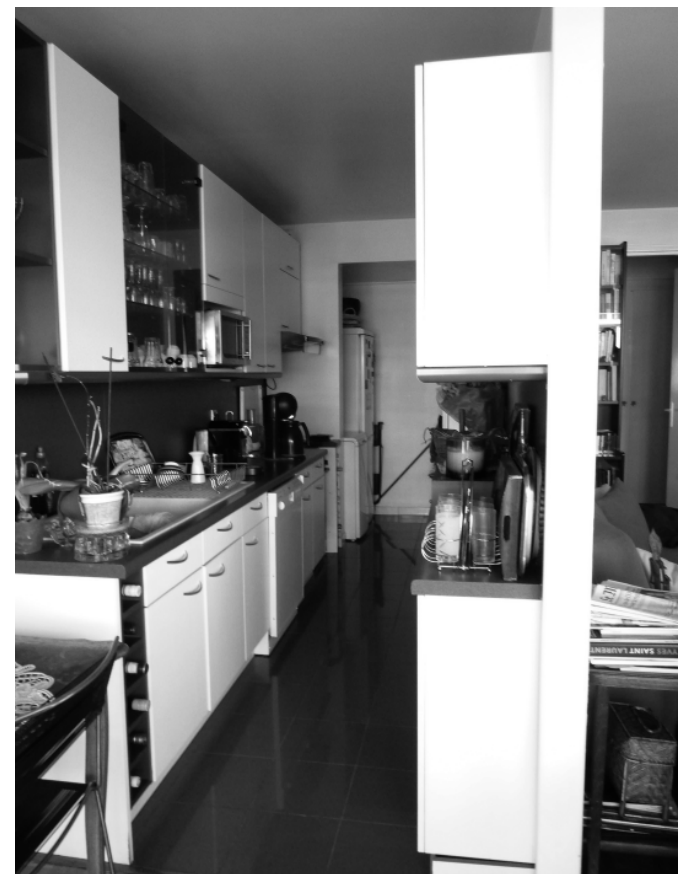

Figura 12

Cocina laboratorio y su «rincón para comer», prolongado por un botellero. Conjunto Maine-Montparnasse II, calle Commandant René Mouchotte. Arquitecto Jean Dubuisson, 1959-1966. Foto Raphaël Salzedo, 2010.

a dos personas. Por lo mismo es una buena cocina para solteros, facilita dar muy pocos pasos, ganar espacio, y es muy económica. Catherine Clarisse muestra no obstante que el trabajo doméstico es allí muy difícil. Concluía en su memoria de Diploma de Estudios Avanzados (DEA) ${ }^{12}$ que las mujeres se benefician en ese lugar de no tener que levantarse sobre la punta de los pies para coger una cacerola, pero que deben de ponerse de rodillas para sacarla del fondo de un armario bajo. Y sin embargo estas cocinas, muy presentes en la vivienda social, continúan construyéndose hoy en día.

12 DEA transformado después en libro: Cuisine, recettes d'architectura, les éditions de l'imprimeur, Besancon, 2004. 


\section{Cocinas y rincón para comer}

En las exposiciones sobre la vivienda que se suceden en el período de entreguerras, las cocinas exhibidas se establecen como «cocinas amuebladas» y frecuentemente como piezas autónomas. Pierre Sonrel da cuenta en su artículo sobre «Las funciones de la vivienda», de las preferencias de los franceses en cuestiones de cocinas y espacios para comer, a partir de una encuesta del Instituto Nacional de Estudios Demográficos (INED) ${ }^{13}$ en la Exposición Internacional del Urbanismo y la Vivienda de 1947: el 50\% de los visitantes hacían la comida en la cocina (y sólo el 34\% de los parisinos), el $45 \%$ en el comedor (y el 59\% de los parisinos). Algunos años más tarde el INED presenta un cuadro de preferencias de los franceses en materia de disposición y lugar de la cocina. La situación no se aleja mucho de la de hoy en día.

Después de la Segunda Guerra Mundial, las experimentaciones sobre la «cocina equipada» comportan finalmente su difusión, sin que se
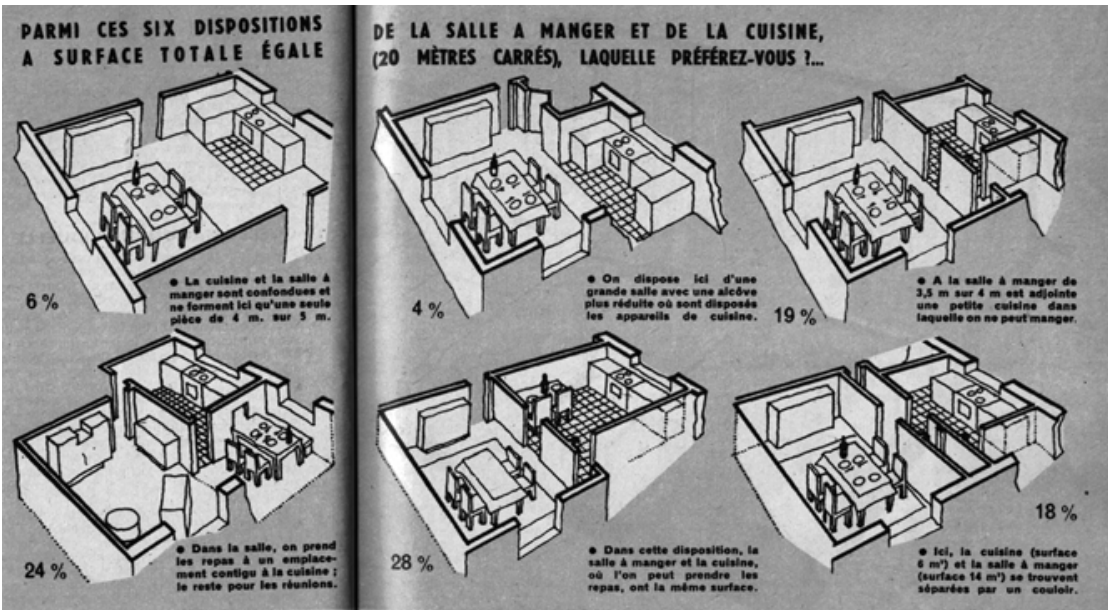

Figura 13

La cocina preferida por los franceses. Encuesta del INED, Sciences et Vie, Hors série, «L'habitation», 1951, pp. 30-31.

13 «Les fonctions de l'habitation», Techniques et Architecture, VII, 5 y 6, 1947, p. 48. 


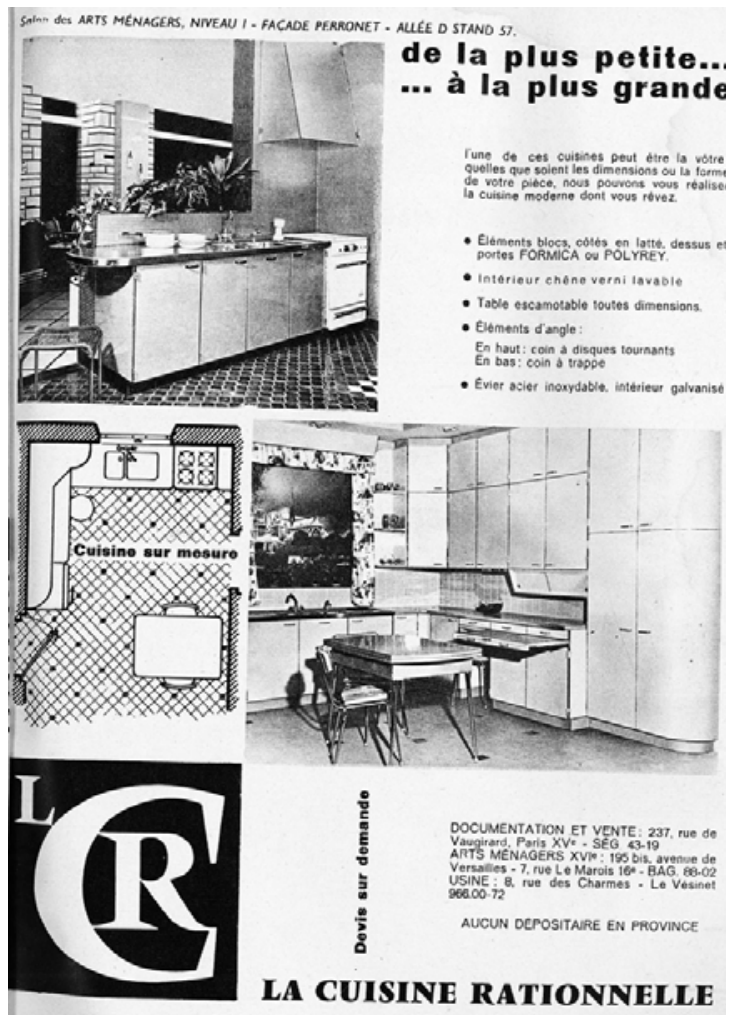

Figura 14

Publicidad de cocina racional y a medida. Arts ménagers, n. ${ }^{\circ}$ 135, marzo 1961.

la nombre todavía de esta forma. En 1961 El arte doméstico resume las posiciones de la época y propone numerosas cocinas equipadas «a medida».

Despues de los años cincuenta, en bastantes viviendas colectivas, herederas de toda esta historia arquitectónica y social, la cocina enriquecida por los epígonos de Le Corbusier, pero también por los de Perret, se ilumina cotidianamente dado que se prolonga a través del rincón para comer que se abre a las fachadas. Está suplantando al comedor, que a partir de ahora se funde con la sala de estar. Otra distribución menos vanguardista, 


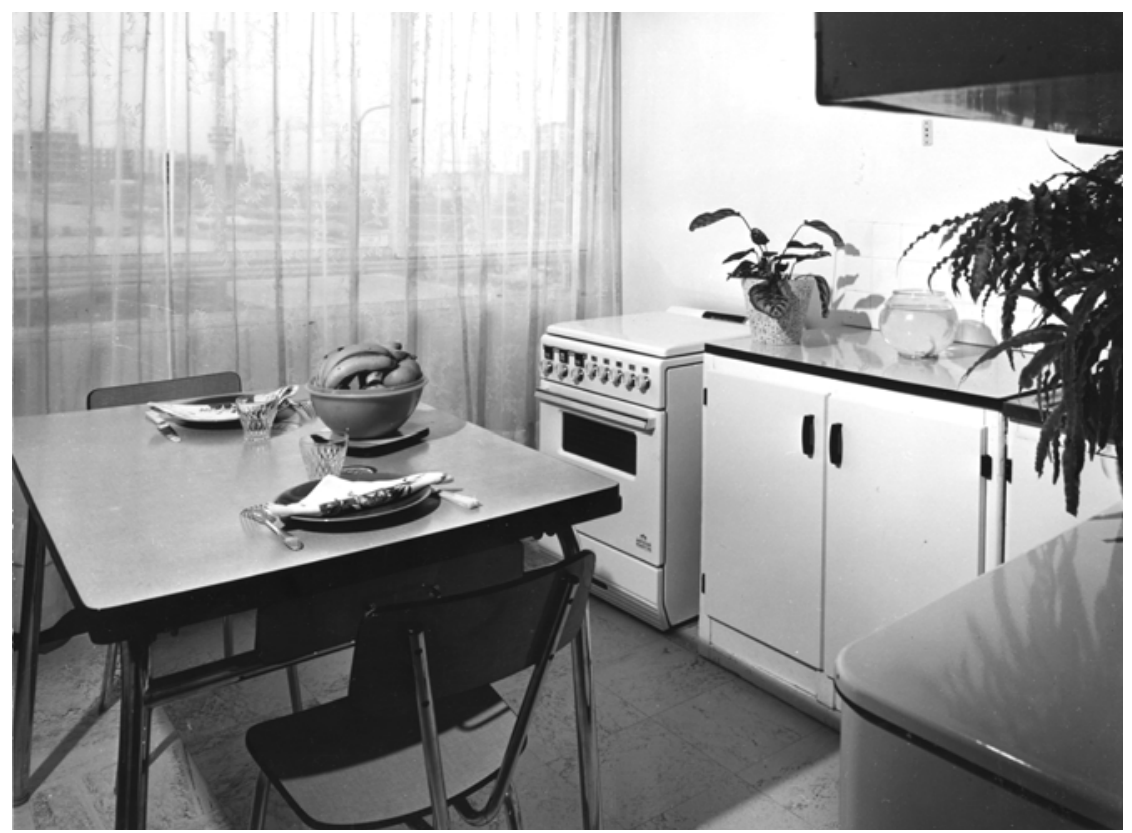

Figura 15

Cocina prolongada hacia un «rincón para comer», en el gran conjunto de los «Lochères», en Sarcelles, 1. ${ }^{a}$ fase, 1956-1961. Arquitectos Robert Boileau y Jacques-Henri Labourdette (Caisse des Dépôts).

sin embargo, continúa estando presente con la cocina situada al otro extremo del pasillo, en los pisos que conservan la división comedor/salón.

Como se ve en el plano de Félix Dumail en Shape village, la cocina está vinculada a la sala de estar por una terrazo o una loggia, elemento importante en la elección de vivienda. Jean Dubuisson, enfrentándose a la misma situación, la concibe en cambio de otro modo: se abre a la vez al pasillo y hacia la mesa de la sala de estar. Estas dos distribuciones, ya propuestas en 1951, se perciben en este momento todavía como muy modernas, incluso nuevas, por numerosos usuarios. Las transformaciones decisivas de la cocina, sin embargo, se han producido hace ya algunas décadas. Hoy en día forma con el salón un único espacio principal en la vivienda. 
De habitación de servicio a rival de la sala de estar. Una pequeña historia...

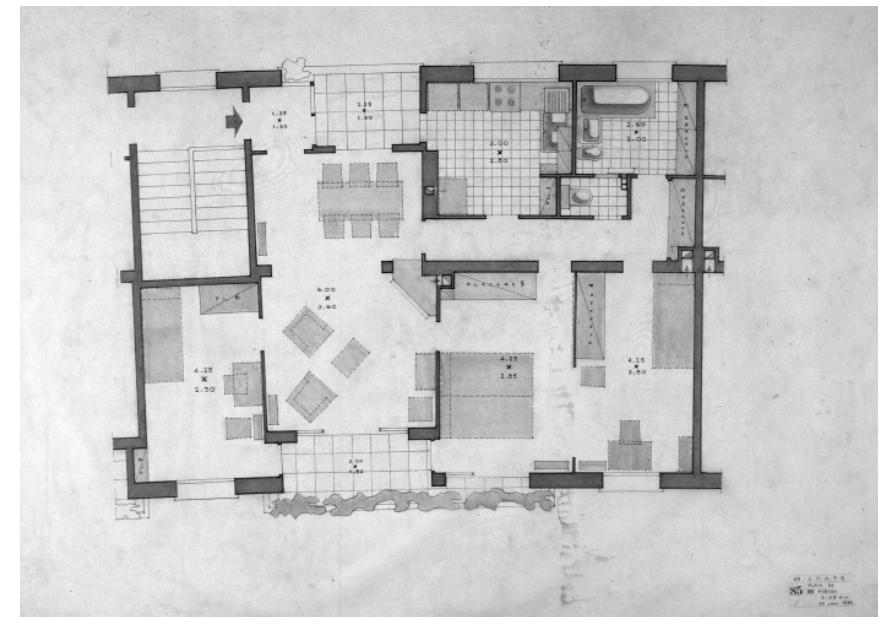

Figura 16

Plano de cocina disociada de la sala de estar, al otro extremo del pasillo. Shapevillage de Saint-Germain-en-Lay, 1951. Arquitecto Félix Dumail. Archivos IFA.

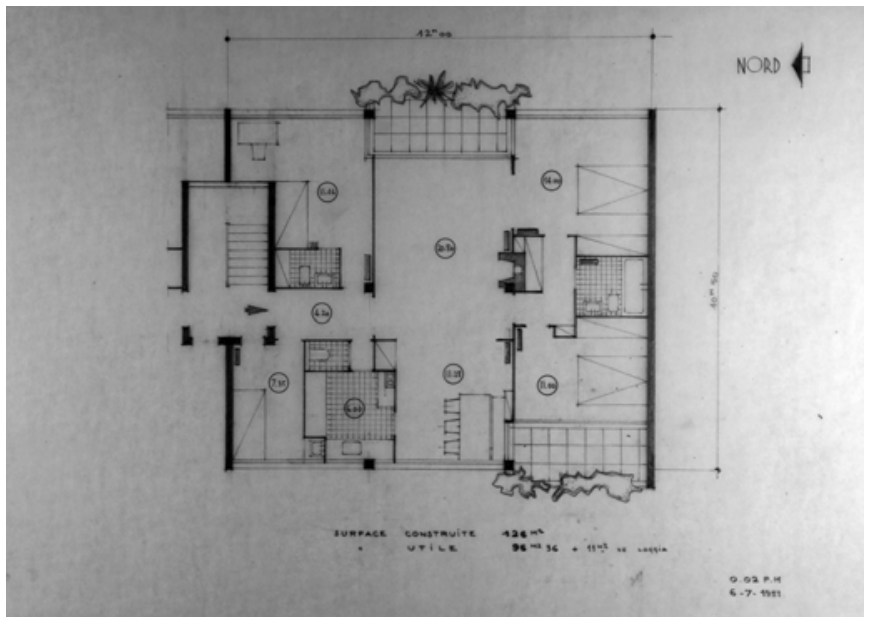

Figura 17

Plano de cocina abierta hacia el pasillo y la sala de estar. Shape-village de Saint-Germain-en-Lay, 1951. Arquitecto Jean Dubuisson. Archivos IFA. 


\section{Una cocina para quedarse: sabores, emociones y secretos compartidos}

Cuando su tamaño lo permite, la cocina llega a ser un lugar de sociabilidad para los adolescentes; la mujer y el hombre reciben allí a sus íntimos cuando el cuarto de estar está ocupado, la pareja se construye allí, y allí hacen los niños sus deberes; un padre y un hijo se hablan sin testigos, etc. Cuando Laprade subraye en 1950 que los usuarios «organizan [la cocina] para vivir en ella» ¡no sabe hasta qué punto acierta! ${ }^{14}$ La tendencia a frecuentar la cocina fuera de las horas de la comida está muy viva hoy; y esta pieza, todavía perfila su denominación. En la misma obra sobre las viviendas colectivas, Pierre Bourget propone denominarla «cocinaestudio» ${ }^{15}$. Sonrel evocaba en 1947 los diferentes términos empleados para designar a las cocinas inglesas; «cocina-living-room» $\left(20 \mathrm{~m}^{2}\right.$ aproximadamente), «cocina-laboratorio» $\left(9 \mathrm{~m}^{2}\right)$, «cerca del living-room donde se come»o «cocina para comer» $\left(12 \mathrm{~m}^{2}\right)^{16}$. Estaríamos ahora en la era de la «cocina-living-room» aunque sin utilizar el término; si bien para muchos esto permanezca todavía como una aspiración que sin embargo se habría conseguido, en el tamaño de la pieza, en las antiguas viviendas colectivas.

La cocina abierta ha sido presentada en los años de 1970 como algo que facilita el compartir las tareas domésticas en la pareja o el grupo doméstico. Ello no significa nada en Francia, puesto que detenta un record en cuanto al número de cocinas abiertas $(32 \% \text { en } 2001)^{17}$ con respecto a sus vecinos europeos, estando como está muy mal colocada en la cuestión de compartir las tareas; y siendo los ingleses, con tan sólo un $20 \%$ de cocinas abiertas, más proclives a compartir el trabajo doméstico.

La cocina es también, para los usuarios que hemos entrevistado a lo largo de estos últimos treinta años, un lugar grato, de intimidad. En la encuesta CSA para Leroy-Merlin en 2001, planteada la cuestión del lugar en donde se hacen confidencias, la cocina ocupa la tercera posición dentro de la casa, después del dormitorio y la sala de estar. Se la describe como una de las piezas más cálidas, pivote del hogar donde se intercam-

14 Albert Laprade, op. cit., p. 6

15 «Les règlements sanitaires», idem., p. 27

16 «Les fonctions de l'habitation», op. cit., p. 248.

17 Cf. la encuesta sobre el mobiliario de los franceses comparado con el de los europeos, en 2001, del Institut de Promotion et l'Etude de l'ameublement (IPEA), en Habitat et Décoration en Europe, abril 2002, y el de 2010 sobre Francia. 
bian conversaciones íntimas, sobre todo cuando cada uno vive a su propio ritmo; mientras que después de la Segunda Guerra Mundial había sido durante mucho tiempo, tal y como lo habíamos visto, un espacio de lo racional, de lo funcional y del ademán calculado, orientado hacia la idea del trabajo doméstico. Se ha querido en algunos momentos del siglo XX hacerla un lugar aséptico, sin huella del trabajo; aunque haya algo morboso en la superhigienización, en la búsqueda de lo vacío, en la «pulcritud del orden ${ }^{18}$, o en la negación a manipular materiales sucios. Pero hoy en día la higiene es una adquisición consolidada, y los valores higiénicos algo ya obsoleto. Por ejemplo ciertos usuarios han vuelto a partir de los años setenta a la cocina adornada, campestre, con decoración de cestos de mimbre, ajos suspendidos, tarros llenos de especias o de alimentos expuestos como en la cocina de una granja.

Con el pretexto de ganar espacio, el concepto de cocina como tal ha sufrido mucho y los términos usados para designarla lo demuestran $\left(\right.$ «rincón-cocina», «kitchenette» $\left.{ }^{19}\right)$ tanto como las distribuciones ampliamente abiertas que la convierten de «pieza» en «espacio». Estos conceptos pueden aparecer como el recurso salvador en el momento de reducir costos, pero esencialmente los reivindican usuarios jóvenes, educados, que hacen alarde de vanguardismo, y que sobre todo no tienen hijos.

Los demás cuando evocan las cocinas abiertas se refieren a las pilas de platos sucios a la vista, a los olores que se cuelan por doquier, al cortinaje de la sala de estar ensuciado por las grasas, a la pérdida del añorado «efecto-sorpresa» cuando se trae un plato a la mesa y a la facilidad del mantenimiento cuando basta con cerrar una puerta. Una de las entrevistadas que ocupaba una vivienda con cocina diseñada como enclave acristalado del salón-comedor expresa de modo conciso lo que piensan muchos: «No tengo ninguna gana que mi cocina sea el elemento decorativo de mi sala de estar».

18 Véase G. Heller sobre la pulcritud suiza: Propre en ordre. Habitation et vie domestique 1850-1930: l'exemple vaudois, Editions D'En Bas, Lausanne, 1979.

19 Traducible por cocinita, y traducido a veces como «cocina americana» o simplemente como cocina pequeña (minicocina) e instalada en un espacio muy reducido. Término híbrido de claro origen anglosajón con sufijo francés, indica bien cómo en dimensiones reducidisimas, se intenta introducir la modernidad consustancial al uso de vocablos anglosajones. Muchas veces consiste en un bloque conteniendo nevera pequeña, fregadero diminuto, 2 placas eléctricas y una cuarta parte dedicada a alacena... Suelen verse las «kitchenette» en los «studios», o apartamentos con pieza única y baño (n. d. t.). 


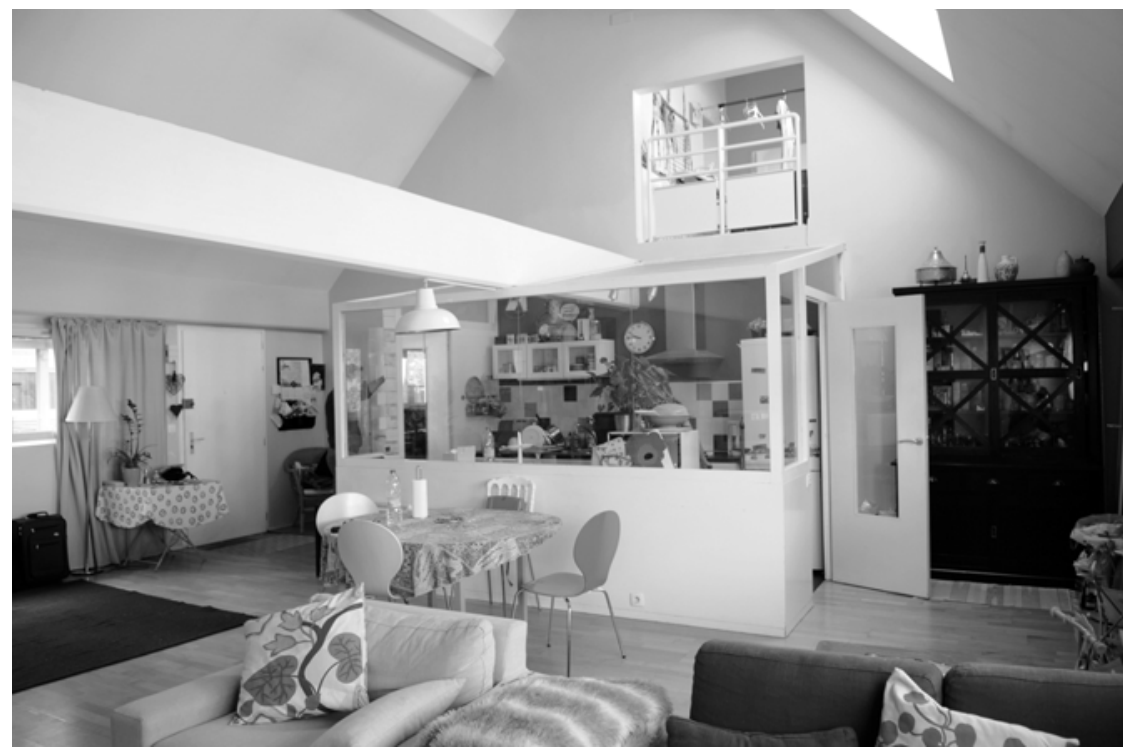

\section{Figura 18}

Cocina transparente como enclave de la sala de estar, en una vivienda social en Saint-Ouen. Arquitectos Jean Nouvel y Pierre Soria, 1986. Foto Raphäel Salzedo.

La batalla causa estragos entre los partidarios de la cocina abierta y los de la gran cocina cerrada, donde se puede instalar una mesa para tomar ciertas comidas ${ }^{20}$, incluso si está ampliamente abierta sobre la sala de estar por puertas o un pasa-platos; solución ideal si se quiere tener una vinculación fácil con la mesa en la sala de estar.

${ }^{20}$ La encuesta del INSEE, muy detallada, acerca de los bienes durables y el amueblamiento en Francia en 1988 indicaba que el 81,4\% de los desayunos se hacían en la cocina, así como el $71,7 \%$ de las comidas del mediodía entre semana, el 63,5\% de las cenas entre semana, el $54,1 \%$ de las comidas del domingo y el $14,4 \%$ de las cenas con invitados. Los habitantes de la región parisina, y sobre todo del mismo París, son los que comen menos en su cocina (por ejemplo solamente hacen el $25,6 \%$ de las comidas del final del día entre semana) en parte debido a la pequeña superficie y la forma de la cocina que no permite instalar una mesa allí. Este tipo de encuesta, desgraciadamente, no ha sido renovada después, aunque participaremos en la próxima con el IPEA. 
De habitación de servicio a rival de la sala de estar. Una pequeña historia...

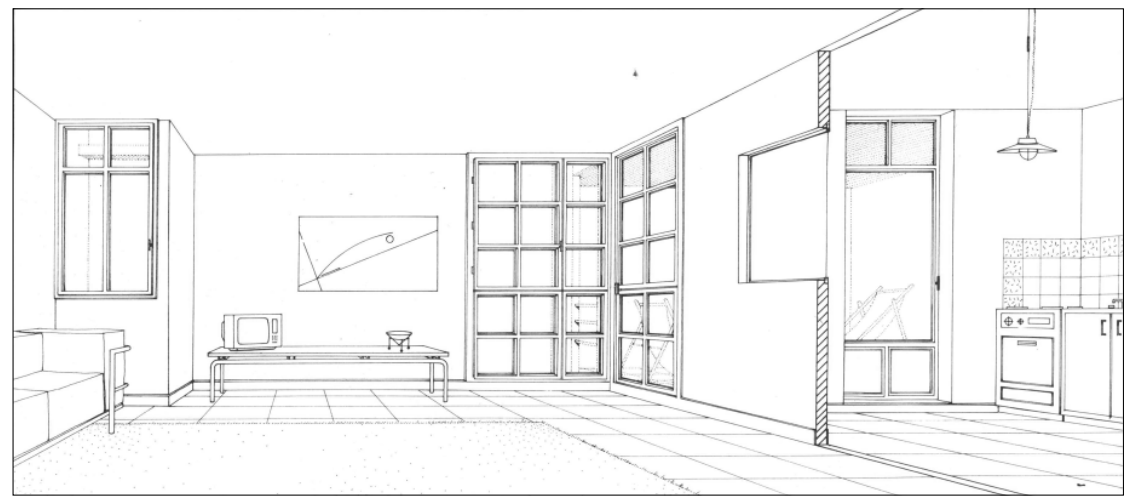

Figura 19

Cocina equipada con pieza pasa-platos en las viviendas colectivas y semi-colectivas, manzana de la Zac du Puiseux, Cergy-Pointoise. Arquitectos

Olivier Brénac y Xavier Gonzalez, 1980-1983. Diseño de los arquitectos.

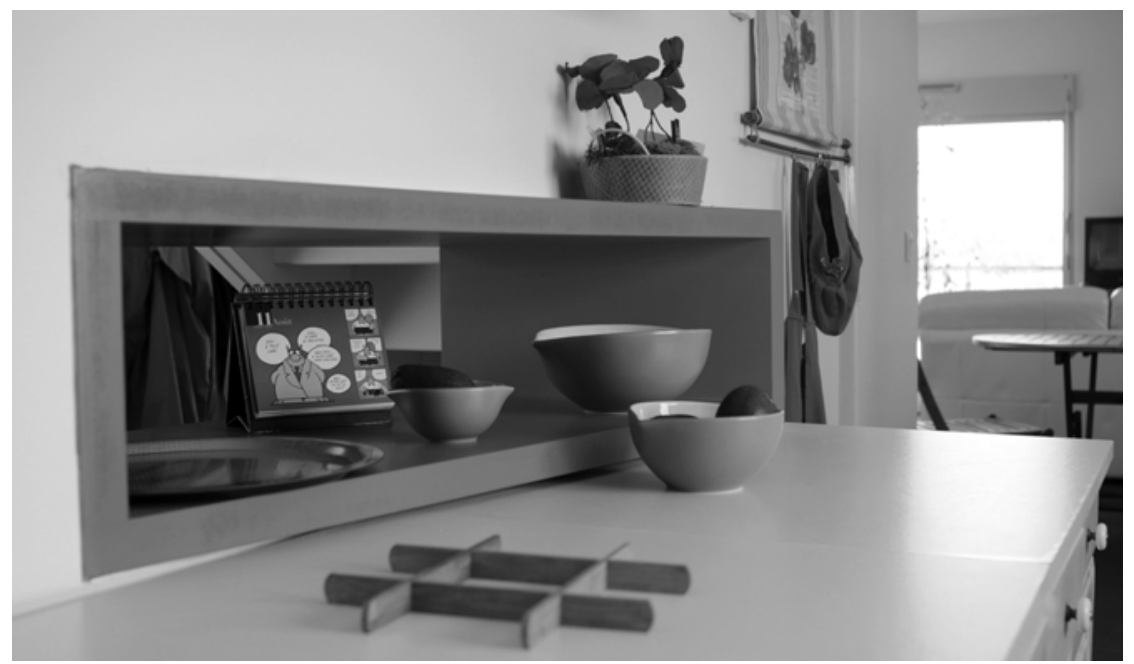

Figura 20

Pasa-platos de la cocina de un edificio de la Cité du Petit Bétheny, Reims (51). Arquitectos Marjolijn y Pierre Boudry, m. o. Le Foyer Rémois, 2007.

Foto Jean-Michel Landecy. 


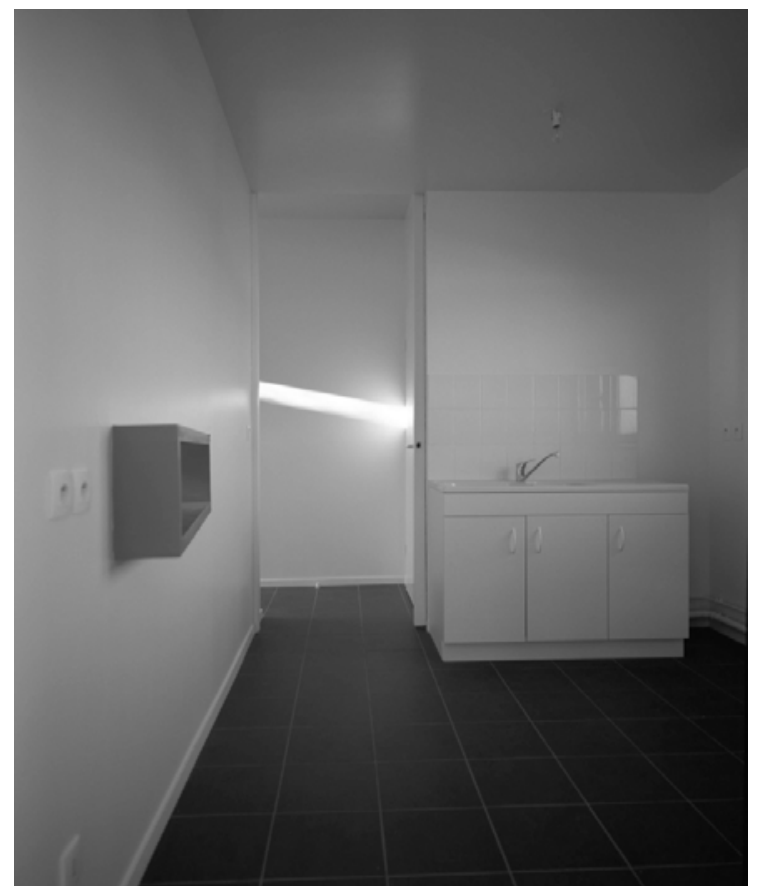

Figura 21

Cocina con pasa-platos, Cité du Petit Bétheny, Reims (51), Arquitectos Marjolijn y Pierre Boudry, m. o. Le Foyer Rémois, 2007. Foto D. R.

Subrayemos que la lavadora se encuentra en la cocina a falta de sitio en la sala de baño. Su proximidad al fregadero provoca hoy quejas entre los franceses, puesto que eso remite a dos tipos de suciedad: la de la ropa y la de las verduras que no pueden ser confundidas.

La cocina equipada ha ingresado en las costumbres cotidianas y ya no representa la vanguardia. Se ve a través de las cocinas de los comercios instaladores, con muebles con ruedas y para los que los conceptos de «fijo» o «móvil» ya no son pertinentes. Hoy cada vez más elementos son móviles incluso si algunos no pueden serlo como el fregadero. Y la costumbre de mezclar muebles verdaderos de cualquier época con los armarios especializados es cada vez más corriente. 


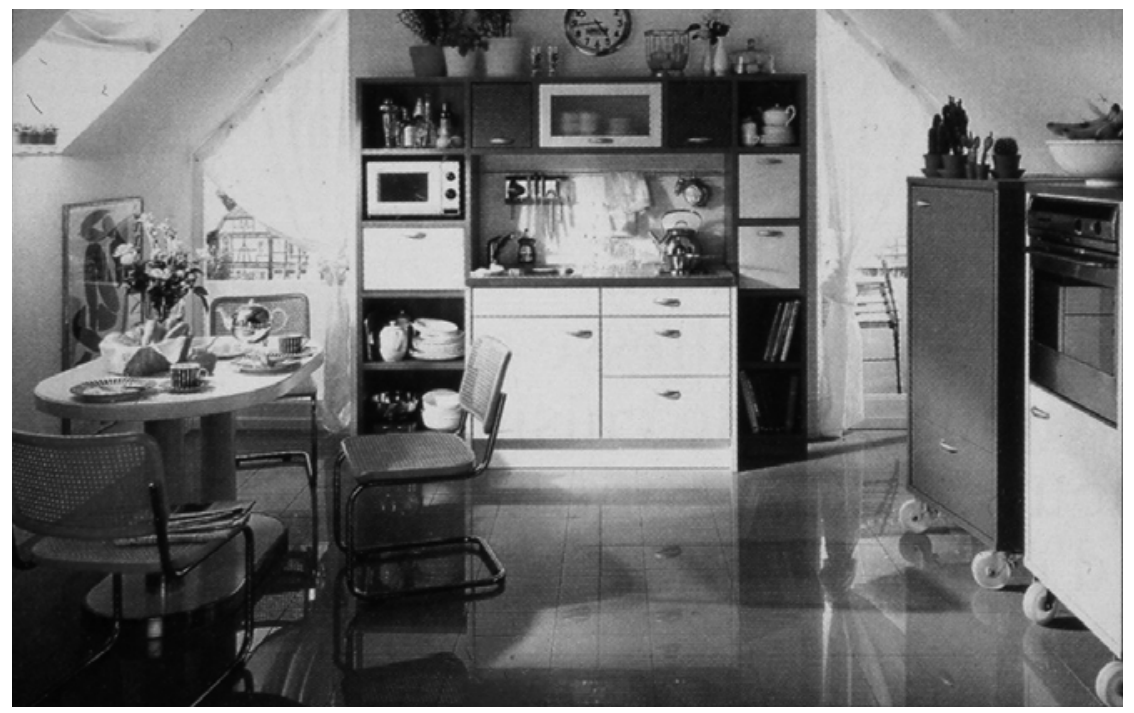

Figura 22

Publicidad de la cocina Contesse, mezclando los armarios de una cocina equipada y muebles de ruedas, c. 2000.

El análisis de Laprade sobre la cocina es premonitorio cuando evoca su posición y orientación en 1950: «Antaño las cocinas estaban al lado de la vista más mala de la casa y al norte. Con la vulgarización de los frigoríficos, estamos convencidos de que más tarde, en los edificios que tengan fachadas al sur y al norte, se pondrán las cocinas-comedor [... ] en el lugar de honor, es decir al mediodía» ${ }^{21}$. La cocina está hoy, como la sala de estar, situada frecuentemente al sur.

A ello se añade ahora las formas de alimentarse, desde la cocina festiva a la bandeja de comida preparada. Se puede hacer cocina rápida o recalentar un plato previamente preparado, pero también pasar seis horas haciendo una fabada o un cuscús. Ello significa que los dispositivos deben adaptarse a ello y multiplicarse. La encuesta del IPEA ${ }^{22}$ en 2001 y en

21 Op. cit. p. 6

22 Se trata de la «Enquête sur l'indice de prix des travaux d'entretien-amélioration de logements» del Ministère de l'Écologie, du Développement Durable et de l'Énergie (n de la t.) 
2010 nos enseña que el 55\% de los franceses comen en la cocina y el $27 \%$ en el comedor. ¿Dónde come el resto? ¿Sobre el sofá viendo la televisión? La mesa eléctrica rodante preconizada desde los años 50 quizá tenga un porvenir al fin y al cabo. La idea de una pequeña cocina móvil, denominada «mesa-buffet» o «mesa rodante», que permite calentar los platos marca su trayectoria, efectivamente, para cenar delante de la televisión sin tener que desplazarse. Desde 1951, la revista Sciences et Vie alaba sus méritos: «Esta mesa buffet rodante, de 0,75 metros de altura, lleva o trae los platos en un solo viaje. Su hornillo de calentar con dos placas de $125 \mathrm{~W}$. mantiene los platos calientes. Sus batientes permiten a dos personas tomar ahí su comida ${ }^{23}$

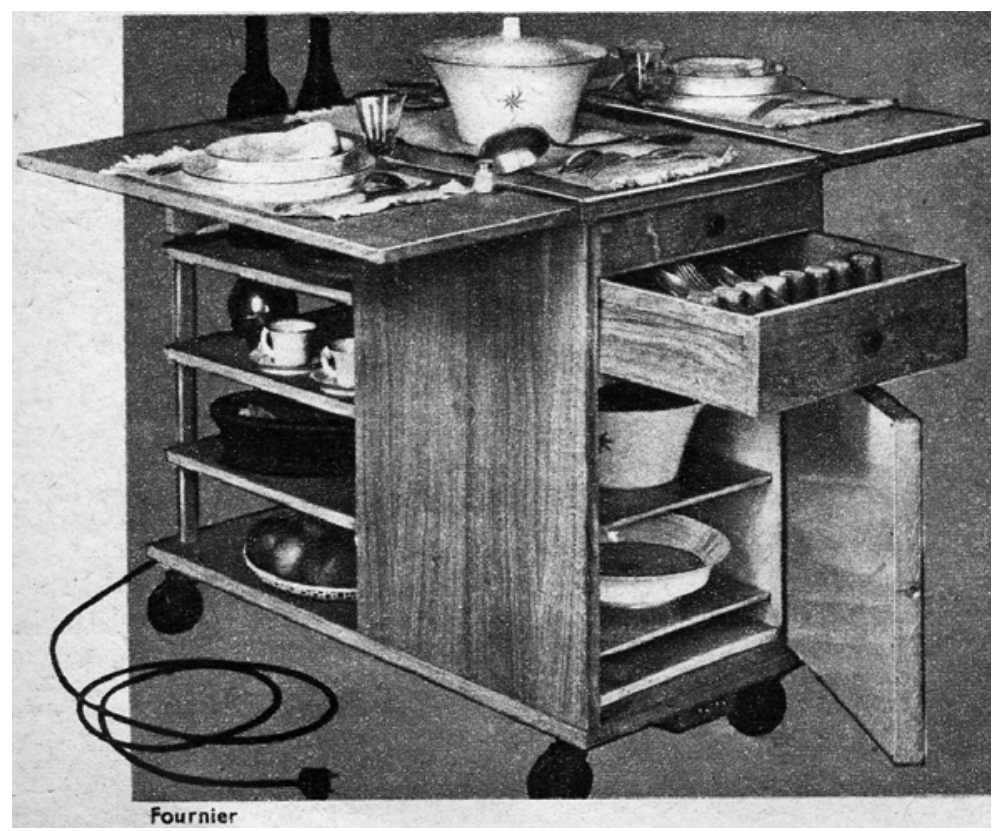

Figura 23

«Mesa-buffet»a ruedas, Sciences et vie, opus cit., 1951, p. 70.

23 Sciences et vie, Hors série, L'habitation, 1951. 
De habitación de servicio a rival de la sala de estar. Una pequeña historia...

Si la cocina ha sido durante largo tiempo un sitio íntimo es también, en nuestra época, un lugar de sociabilidad y de demostración de estatus. En la medida en la que los usuarios han invertido mucho tiempo y dinero para concebirla y decorarla, quieren mostrarla. En cien años la cocina ha pasado de ser una pieza a esconder a una pieza a enseñar. La cocina, en consecuencia, ha remplazado, cuando su superficie lo permite, al comedor en su papel como rival de la sala de estar. 